In the Public Eye

\title{
Patients may gain access to doctors' disciplinary data
}

Deborah Josefson, San Francisco

Patients in the United States may soon be able to access currently protected information about their doctors, including malpractice data, if a bill introduced through Congress is passed.

Representative Tom Bliley (R-Va), chair of the House commerce committee, spearheaded controversial legislation that allows the public to have access to the National
Practitioner Data Bank. The legislation enters delicate territory, where it is important to balance consumers' right to knowledge and physicians' right to privacy and protection against libel.

The data bank was set up by Congress in 1986. Its aim was to facilitate both peer review and the process for licensing physicians. Access to the database has been limited to hospitals, insurance companies, state medical boards, and physicians seeking information about themselves.

Currently, the database collects information such as adverse disciplinary actions taken by state medical and dental boards, suspensions of clinical privileges by hospitals, medical malpractice liabilities, exclusions from participating in Medicaid and 


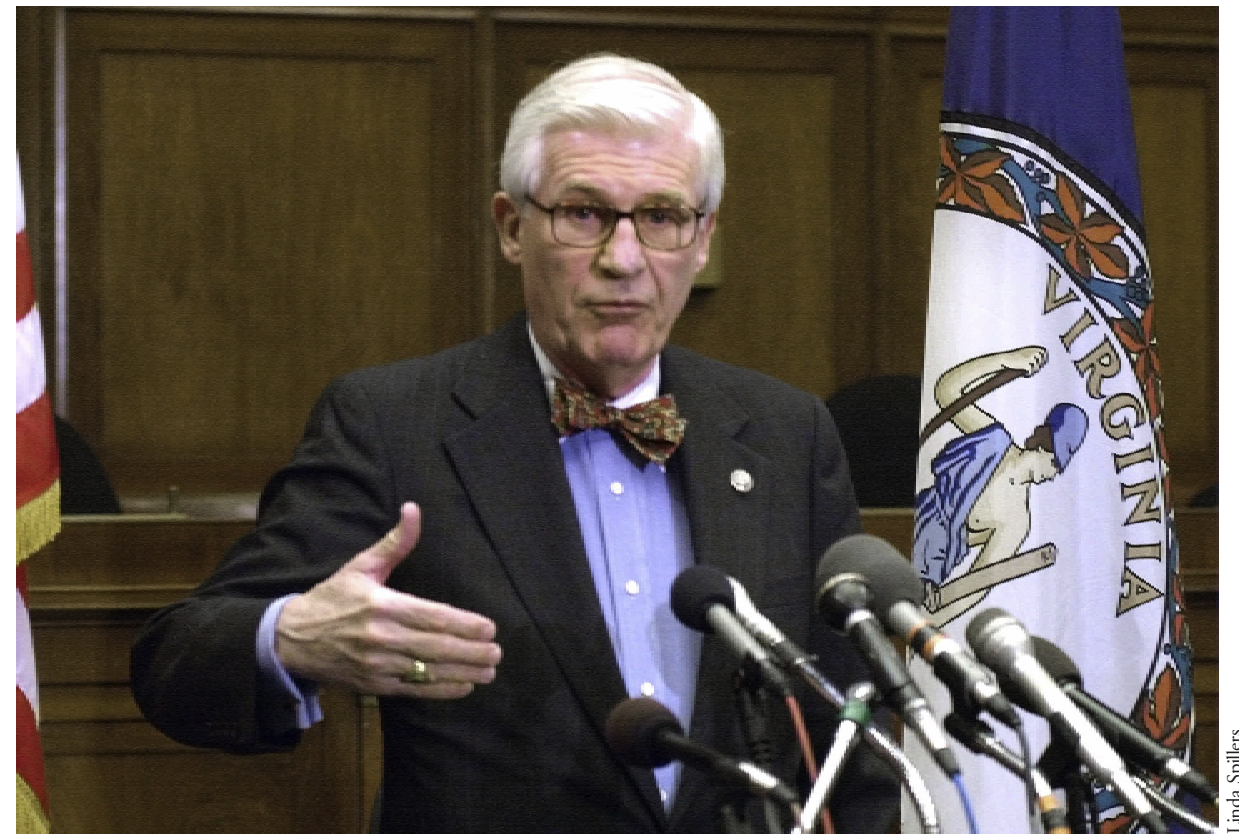

Tom Bliley is spearheading the controversial legislation

Medicare programs, and actions taken by the Drug Enforcement Agency against the practitioner.

In the United States, physicians who lose their license in 1 state can cross state lines and practice in another state. The data bank allows states to find out if a license to practice has been revoked by another state and thus facilitates the licensing process. Although access to the bank is restricted, more than 30 state medical boards allow consumers to query them on the status of doctors practicing in their states.

The drive to make the national database public comes on the heels of several wellpublicized examples of disturbed or incompetent doctors who were still practicing medicine. Chief among these was the case of a respected neurosurgeon who operated on the wrong patient and removed healthy instead of tumor tissue. Another case was that of Dr Alan Zarkin, an obstetrician and gynecologist, who carved his initials on a patient's ab- domen after performing a cesarean section. He continued to practice for 5 months afterward, despite dismissal from the staff of the hospital where the incident occurred.

Proponents of a public database argue that it will allow consumers to make more informed decisions when choosing their doctors. Physicians' groups, such as the American Medical Association and the American Osteopathic Association, however, point out that the information in the database is useless for this purpose because it is out of context.

Three quarters of the information in the data bank concerns malpractice suits. Malpractice information can be misleading because the number and size of settlements do not necessarily reflect a physician's competence.

Moreover, a recent study in The New England Journal of Medicine found that only 1 in 5 malpractice suits is settled with an admission of the physician's negligence. Insurance companies often settle suits to avoid costlier court cases, and thus, the mere existence of a suit or settlement does not reflect the merits of the litigation.

Physicians in high-risk specialties, such as surgeons and obstetricians and gynecologists, or those who take on sicker patients and conduct cutting-edge clinical research, may also face higher malpractice rates than the average general practice doctor. Consumers who screen out such physicians on the basis of a high number of suits deprive both themselves and the doctors, the organizations say.

An Associated Press review of the data bank earlier this year found about 500 physicians and dentists who had been slapped with at least 10 disciplinary actions or malpractice suits in the past decade. After that, the New York Daily News featured several of these physicians in a front-page article.

In a Congressional hearing on the matter, Dr Charles Norwood, a surgeon and member of Congress, voiced his concerns: "Making the National Practitioner Data Bank [NPDB] public is an asinine idea because it attaches a level of sophistication to the database which is not appropriate and ignores state-based approaches that make more sense and are already in place today. The NPDB is simply gathered information. It has no context. Information does not in any way explain the conditions behind judgments made in specific cases."

Others are concerned that if the data bank is made public, doctors will be discouraged from self-reporting their errors and those of their peers.

Despite these concerns, efforts to open the bank continue. Congressman Bliley hopes to model the public version on the Massachusetts Physician Profiles project that allows consumers access to information about physicians' malpractice suits and criminal actions (www.massmedboard.org) and to push the bill through Congress before the end of the year.

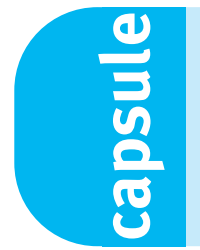

Research on race must use justified definitions Editors at the Canadian Medical Association Journal (2000;162:1393) urge researchers to stop using meaningless descriptors such as "black" and "white" when describing the participants in their research. Unsophisticated references to race are biologically unsound and unlikely to be relevant to the research question, they say. Use of all ethnic descriptors must be scientifically justified and clearly explained. 